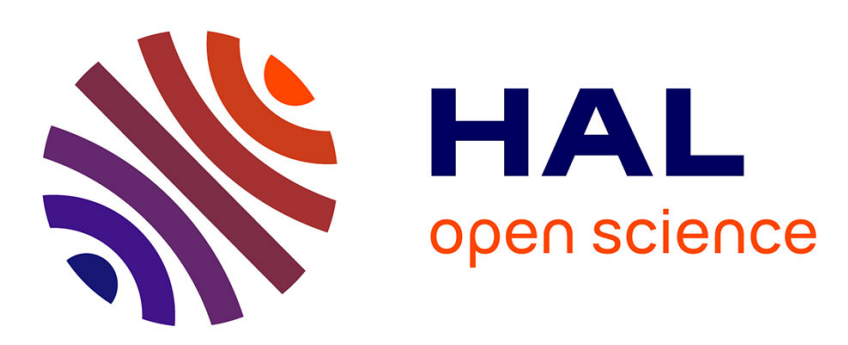

\title{
Emotional pictures impact repetitive sprint ability test on cycle ergometre
}

Laure Coudrat, Majdi Rouis, Hamdi Jaafar, Elvis Attiogbé, Thierry Gélat, Driss Tarak

\section{- To cite this version:}

Laure Coudrat, Majdi Rouis, Hamdi Jaafar, Elvis Attiogbé, Thierry Gélat, et al.. Emotional pictures impact repetitive sprint ability test on cycle ergometre. Journal of Sports Sciences, 2014, 32 (9), pp.892-900. 10.1080/02640414.2013.865253 . hal-01344542

\section{HAL Id: hal-01344542 \\ https://hal.univ-lorraine.fr/hal-01344542}

Submitted on 23 Oct 2019

HAL is a multi-disciplinary open access archive for the deposit and dissemination of scientific research documents, whether they are published or not. The documents may come from teaching and research institutions in France or abroad, or from public or private research centers.
L'archive ouverte pluridisciplinaire HAL, est destinée au dépôt et à la diffusion de documents scientifiques de niveau recherche, publiés ou non, émanant des établissements d'enseignement et de recherche français ou étrangers, des laboratoires publics ou privés. 


\section{TITLE PAGE}

\section{Emotional pictures impact repetitive sprint ability test on cycle ergometre}

\section{Interaction between emotion and power output}

Laure Coudrat, ${ }^{1,2}$ Majdi Rouis, ${ }^{1,3}$ Hamdi Jaafar, ${ }^{1}$ Elvis Attiogbe, ${ }^{1}$ Thierry Gélat, ${ }^{1}$ and Tarak Driss ${ }^{1}$

${ }^{1}$ Centre de Recherches sur le Sport et le Mouvement (CeRSM), EA 2931, Equipe «Analyse du mouvement en Biomécanique, Physiologie et Imagerie », UFR STAPS, Université Paris Ouest Nanterre La Défense, France

${ }^{2}$ Laboratoire de Recherche Adaptations physiologiques à l'exercice et réadaptation à l'effort, EA3300, UFR STAPS, Université de Picardie Jules Vernes, Amiens, France

${ }^{3}$ Laboratoire d'Etudes de la Motricité Humaine, Faculté des Sciences du Sport et de l’EP, Université de Lille, Ronchin, France

Keywords: power output, repetitive sprint ability test, affective load, emotion

Word count: 3768 


\section{ABSTRACT}

This study investigated the interaction between emotional eliciting pictures and power output during a repetitive supra-maximal task on a cycle ergometre.

Twelve male participants (mean $( \pm \mathrm{SD})$ age, height and weight: $28.58 \pm 3.23$ years, $1.78 \pm 0.05 \mathrm{~m}$ and $82.41 \pm 13.29 \mathrm{~kg}$ ) performed five repeated sprint tests on a cycle ergometre in front of neutral, pleasant or unpleasant pictures. For each sprint, mechanical (peak power and work), physiological (heart rate) and perceptual (affective load) indices were analysed. Affective load was calculated from the ratings of perceived exertion and reflected the amount of pleasant and unpleasant responses experienced during exercise. The results showed that peak power, work and heart rate values were significantly lower $(P<0.05)$ for unpleasant pictures $(9.18 \pm 0.20$

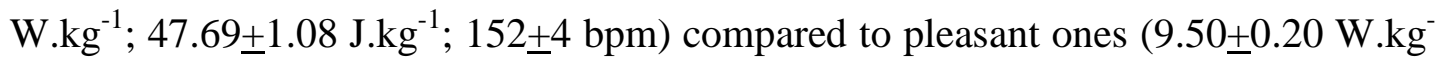
$\left.{ }^{1} ; 50.11 \pm 0.11{\mathrm{~J} . \mathrm{kg}^{-1}}^{-1} 156 \pm 3 \mathrm{bpm}\right)$. Furthermore, the affective load was found to be similar between the pleasant and unpleasant sessions.

All together, these results suggested that the ability to produce maximal power output depended on whether the emotional context was pleasant or unpleasant. The fact that the power output was lower in the unpleasant vs pleasant session could reflect a regulatory process aimed at maintaining a similar level of affective load between both sessions. 


\section{Introduction}

Sports performance depends not only on the ability to produce a maximal or nearmaximal effort but also on the ability to repeat it. These skills could be measured by cycling laboratory tests such as the repetitive sprint ability (i.e. RSA) test (Bishop, Spencer, Duffield, \& Lawrence, 2001). Performance in such a test, estimated from the power output, depends on several factors such as recovery patterns (Billaut \& Basset, 2007), previous fatiguing (Mendez-Villanueva, Hamer, \& Bishop, 2007), or time of the day (Racinais, Connes, Bishop, Blonc, \& Hue, 2005). For example, in this latter study, the peak power developed in the first sprint was higher in the evening than in the morning. Otherwise, it has been recently suggested that power output was also affected by the knowledge of sprint number (Billaut, Bishop, Schaerz, \& Noakes, 2011). These findings demonstrated the existence of a pacing strategy managing the total energy expenditure during exercise in order to ensure that the exercise bout can be completed with the maximal performance and without a catastrophic biological failure (St clair Gibson \& Noakes, 2004; Noakes, St Clair Gibson, \& Lambert, 2005). From the central governor model (CGM) (Noakes et al., 2005), this pacing strategy is thought to be controlled by the brain and selected according to internal (e.g. from peripheral physiological systems) and external (e.g. environmental conditions) information (St Clair Gibson \& Noakes, 2004; St Clair Gibson et al., 2006; Noakes et al., 2005). Among this information, the conscious sensory perception of fatigue may have a crucial role (Baron, Moullan, Deruelle, \& Noakes, 2011; St Clair Gibson \& Noakes, 2004).

Interestingly, based on the hypothesis that rating of perceived exertion (RPE) has an affective component (Baden, McLean, Tucker, Noakes, \& St Clair Gibson, 2005; St Clair Gibson et al., 2006), Baron and colleagues (Baron et al., 2011) 
recently proposed an affective loading scale computed on the basis of RPE. Affective loading is here defined as the difference between negative and positive affect arising from the exercise intensity and represent internal information that contributes to the regulation of pacing strategy. In this framework, the authors suggested that the more positive the affective responses during exercise, the greater the desire to maintain or to increase the exercise intensity. In contrast, the more negative the affective responses, the lesser this desire, resulting in a performance decrease. The role of this emotion-motivational process has been studied under conditions where changes in emotional state stemmed from the exercise intensity and not from external sensory information (Smith \& O'Connor, 2003; Tian \& Smith, 2011). For example, affective valence of the experienced exercise was less pleasant during a high intensity (i.e. $105 \%$ of ventilatory threshold) compared to a low intensity (i.e. $85 \%$ of ventilatory threshold) cycling bout, suggesting that affective responses were less pleasant and the desire to maintain the exercise was lower during a high intensity exercise (Kilpatrick, Kraemer, Bartholomew, Acevedo, \& Jarreau, 2007). From another point of view, other studies showed that unpleasant emotions such as anxiety and anger might be used for enhancing performance, from emotion regulation strategies (Lane, Beedie, Jones, Uphill, \& Devonport, 2012).

Furthermore, it has been hypothesized that emotional motivation, such that involved by appetitive and defensive motivational systems (Lang, Bradley, \& Cuthbert, 1997), was activated by pleasant and unpleasant external sensory information (e.g. emotional pictures), respectively, contrasting with emotional motivation arising from effort intensity. In this framework, many studies showed that emotional information could have some beneficial or deleterious effects on many goal-directed movements such as those involved in button press tasks (Pereira et al., 
2006), arm movement (Chen \& Bargh, 1999; Coombes, Cauraugh, \& Janelle, 2006) and gait initiation (Gélat, Coudrat, \& Le Pellec, 2011; Stins \& Beek, 2011). In these studies, the impact of emotion on motor performance, measured in terms of reaction time, accuracy and amplitude of motor responses, usually depended on the congruency between the direction of the considered movement (i.e. approach, avoidance) and the valence of stimuli. To the extent that supra-maximal exercises are often produced without any approach-avoidance direction, one study appears to be particularly interesting as emotional effects were analysed on a non-directional arm movement such as a square-tracing task (Coombes, Janelle, \& Duley, 2005). In Coombes et al.'s study, an extended exposure to unpleasant pictures (i.e. 8 s) decreased the movement accuracy (i.e. greater error). This result illustrated a deleterious effect of unpleasant stimuli on performance, resulting from the defensive motivational system activation.

To our knowledge, while sports competitions are performed in varied emotional contexts, no study has investigated the role of external emotional information during supra-maximal exercise. The potential role of emotional information to change power output during supra-maximal exercise might have strong implications on training.

The aim of the present study was to explore the effect of continued emotional information on a non-directional movement: a repetitive supra-maximal task on a cycle ergometre. Emotional context was modulated by a display of neutral (i.e. control condition), pleasant and unpleasant pictures, traditionally used to induce emotion. Based on Baron's model and the results of Coombes, we hypothesized that peak power and work should be greater in a pleasant context, compared to an unpleasant one. 


\section{Methods}

\subsection{Participants}

Twelve active and healthy men practicing recreational sporting activities for about 4$5 \mathrm{~h}$ a week (jogging, soccer) volunteered for this study. None of them were cyclists. Their mean $( \pm \mathrm{SD})$ age, height and weight were $28.58 \pm 3.23$ years, $1.78 \pm 0.05 \mathrm{~m}$, and $82.41 \pm 13.29 \mathrm{~kg}$, respectively. Each participant signed an informed consent before the experimental procedures. The study complied with the Helsinki Declaration for human experimentation and was approved by the Institutional Review Board of the University.

\subsection{Experimental design}

Three days after experienced a familiarization session, participants completed three test sessions in a randomized order: a neutral, a pleasant and an unpleasant one (2 days apart). Thus, 6 possible combinations were performed: neutral-pleasantunpleasant, neutral-unpleasant-pleasant, pleasant-neutral-unpleasant, pleasantunpleasant-neutral, unpleasant-neutral-pleasant and unpleasant-pleasant-neutral, with 2 participants per combination. Each session consisted of a warm-up and a RSA cycle test (Bishop et al., 2001).

\subsubsection{Warm-up}

The standardized warm-up consisted of $5 \mathrm{~min}$ of cycling at $80 \mathrm{~W}$, followed by $3 \mathrm{~min}$ of rest and then a 10-s maximal sprint test on cycle ergometre. Upon completion of the 10-s test, participants rested for 5 min before performing the RSA cycle test. Importantly, participants were required to gaze horizontally during the 10-s maximal 
sprint test. This instruction served as training the participants to keep their gaze horizontally during the subsequent RSA cycle test, for which a projected picture had to be viewed during each 6-second sprint. The participants were informed that if their head got down during the RSA test, then the trial would be discarded.

\subsubsection{RSA cycle test}

Each RSA cycle test consisted of 5 x 6-s sprints separated each by 24-s of passive recovery period on a cycle ergometre (Monark 894E, Stockholm, Sweden). Load was set at 60 g. $\mathrm{kg}^{-1}$ of body mass on the basis of previous results showing that a load between 50 and $75 \mathrm{~g} . \mathrm{kg}^{-1}$ of body mass is suitable for the determination of maximal power in active adults (Doré et al., 2000).

Participants were seated on the cycle ergometre placed at a distance of $2.50 \mathrm{~m}$ in front of a white wall of the laboratory on which visual stimuli was presented. The temperature was $22^{\circ} \mathrm{C}$.

At trial onset, adjustments to saddle height, foot position on pedals, and upper body position were made according to each subject's satisfaction. Toe clips and heel straps were used to prevent the feet from slipping. The optimal riding position was maintained identical throughout the study. The start and end of each sprint was performed according to the onset and the extinction of a single visual stimulus, respectively. Participants were instructed (1) to assume the ready position while awaiting the start visual signal, (2) to pedal as soon as and as fast as possible after stimulus onset, (3) to perform an all-out effort throughout the duration of the stimulus presentation and (4) to look at the stimulus the entire time it was on the wall, i.e. do not get the head down during the 6-s sprint test. 


\subsubsection{Stimuli presentation}

SuperLab Pro v.2 was used to control the visual stimuli presentation of each sprint which began with a 4-s preparatory period, characterized by the display of a fixation cross, followed by a 6-s visual stimulus $(95 \mathrm{~cm} \times 160 \mathrm{~cm})$. During the familiarization session, the visual stimulus was a white square. During the three test sessions, it was a neutral, pleasant or unpleasant image. Thus, 15 images were selected from the International Affective Picture System (IAPS) according to their normative ratings for male participants (Lang, Bradley, \& Cuthbert, 2005). These images represented neutral people for the neutral session, sports images for the pleasant session and mutilation for the unpleasant session.

According to the IAPS model, valence of each image category was chosen by the experimenter as significantly different from each other $(P<0.05)$. Sports images (6.9) were rated as more pleasant than neutral people images (5.1), which were rated as more pleasant than mutilation ones (2.2). However, while the arousal of sports and mutilation pictures were not significantly different $(P=0.480)$, neutral people images were rated as less arousing $(P<0.0001)$ than both sport and mutilation images (neutral people: 3.2, sport: 6.1, mutilation: 5.8). IAPS image numbers were: i) neutral, 2102, 2191, 2383, 2513, 2570; ii) pleasant, 8060, 8090, 8200, 8210, 8260; iii) unpleasant, 3015, 3051, 3062, 3068, 3100.

Immediately following the completion of all sessions, a computerized 9-point version of the self-assessment manikin (SAM) (Lang et al., 2005) was used to obtain subjective ratings of valence and arousal of all images viewed during the sessions. In this system, ratings of valence are indicated by five graphical representations of facial expressions ranging from a severe frown (most unpleasant) to a broad smile 
(most pleasant). For the arousal, the manikin varies from a state of low to high agitation. Participants may select any of the five figures, or boxes in between.

\subsection{Variables}

\subsubsection{Mechanical indices}

The Monark cycle ergometer interfaced with a microcomputer was used to collect the data and to calculate the power and the work performed during each sprint.

The peak power output $\left(\mathrm{P}_{\text {Peak }}\right)$ elicited during each sprint was calculated from the relationship between the peak pedal velocity and the braking force as described by Vandewalle and colleagues (Vandewalle, Peres, Heller, \& Monod, 1985). The mechanical work (W) performed during each sprint was calculated by the integral of the power vs. time curve.

Two decrement values were calculated by considering all sprints: the decrement in peak power output $\left(\mathrm{PP}_{\mathrm{dec}}\right)$ and the decrement in work done $\left(\mathrm{W}_{\mathrm{dec}}\right)$ using the following equations: (Bishop et al., 2001; Fitzsimmons, Dawson, \& Ward, 1993)

$$
\begin{gathered}
P P_{\text {dec }}(\%)=\left\{1-\frac{\text { sum of PPeak }}{5 \times \text { best PPeak }}\right\} \times 100 \\
W_{\text {dec }}(\%)=\left\{1-\frac{\text { total } W}{5 \times \text { highest } W}\right\} \times 100
\end{gathered}
$$

\subsubsection{Physiological and perceptual responses to exercise}

The heart rate (HR) was continuously measured during each trial using a heart rate monitor with 1-second frequency (Polar RS400, Polar Electro Oy, Kempele, Finland) strapped to the chest wall directly above the heart. The peak of heart rate was obtained for each sprint. 
For each 6-s sprint, participants were asked to rate their subjective perceived exertion (RPE) using the 6-20 point Borg scale (Borg, 1982). The end of each 6-s sprint corresponded to the offset of a picture. At this time, the RPE scale appeared on the wall and participants had to give one number from 6 to 20 after each 6-s sprint. According to Baron and colleagues (Baron et al., 2011) and considering affect as bipolar, RPE scores allowed to calculate the affective load defined as the difference between the coexisting negative and positive affective responses associated to the exercise. As RPE score indicates a physical discomfort, it directly reflects the amount of unpleasant affective (UA) responses, which cannot be lower than 6 (very very light) and greater than 20 (very very hard). Pleasant affective (PA) responses could be thus deduced from the amount of UA responses. For instance, if the RPE score is equal to 6 , then PA responses will be equal to 14 . In this case, affective load computed as the difference between UA and PA responses, will be equal to - 8 . At the opposite, if the RPE score is equal to 20, then PA responses will be equal to 0 . In this case, affective load will be equal to 20 . A negative affective load score indicates the dominance of pleasant affective responses whereas a positive affective load score indicates the dominance of unpleasant ones.

\subsubsection{Emotional bias scores}

In order to assess the positive or negative effect of emotional pictures on performance, two indexes were created for each dependent variable: a pleasant and an unpleasant effect bias scores. They were calculated as the value associated to the pleasant or unpleasant context, respectively, minus the value associated to the neutral one (Fox, 2002; Naugle, Joyner, Hass, \& Janelle, 2010). A positive score indicates greater values during an emotional relative to a neutral context while a negative 
score indicates reduced values during the emotional relative to a neutral context. The bias scores served as the bases for all statistical analyses.

\subsection{Statistical analysis}

Analyses were performed using Statistica 7.1 software for windows (StatSoft, France). Data distribution normality was confirmed with the Kolmogorov-Smirnov distance test. Bias scores for $\mathrm{PP}_{\text {eak }}, \mathrm{W}, \mathrm{HR}$ and affective load were analysed using a two-way (emotional pictures: pleasant, unpleasant) $\mathrm{x}$ five (sprints) analysis of variance (ANOVA) with repeated measures on the two factors. $\mathrm{PP}_{\mathrm{dec}}$ and $\mathrm{W}_{\mathrm{dec}}$ bias scores were analysed using a one-way repeated-measures ANOVA (emotional pictures: pleasant, unpleasant).

The difference between the ratings of self-reported valence and arousal of each image category was analysed using one-way repeated-measures ANOVA (image categories: neutral, pleasant and unpleasant).

Post hoc analyses were conducted using the Bonferroni test. For all analyses, the probability was set at $P<0.05$. Effect sizes were calculated as partial eta-squared $\eta_{p}{ }^{2}$ to estimate the meaningfulness of significant findings.

\section{Results}

\subsection{Pictures ratings and affective load bias score}

The one-way ANOVA performed on the ratings of self-reported valence (SAM procedure $)$ revealed a main effect of image category $\left(\mathrm{F}_{2,22}=156.45, P<0.0001\right.$, $\left.\eta_{p}{ }^{2}=0.93\right)$. Post hoc test showed that valence for pleasant image $(6.3 \pm 0.4)$ was 
significantly higher $(P=0.01)$ than neutral images $(5.3 \pm 0.2)$; the latter being significantly higher $(P<0.0001)$ than unpleasant ones $(1.2 \pm 0.1)$.

The one-way ANOVA performed on the ratings of self-reported arousal also revealed a main effect of image category $\left(\mathrm{F}_{2,22}=93.81, P<0.0001, \eta_{p}{ }^{2}=0.89\right)$.

In contrast with normative arousal ratings (IAPS), post hoc test demonstrated that pleasant images $(4.5 \pm 0.5)$ were rated as less arousing $(P<0.0001)$ than unpleasant ones $(7.8 \pm 0.3)$. Neutral images $(2.3 \pm 0.4)$ were rated as less arousing $(P<$ 0.0001) than pleasant and unpleasant images.

Regarding the affective load bias score, the two-way ANOVA revealed no main effect of image $(P=0.088)$ despite a trend indicating that the affective load value was lower for pleasant pictures $(0.43 \pm 0.50)$, compared to unpleasant ones $(1.73 \pm 0.58)$ (Table 1). No main effect of sprint and no interaction were found on this variable $(P>0.05)$.

\subsection{Mechanical and physiological bias scores}

Table 1 presents summary data for all these dependent variables.

$* * * *$ Table 1 near here $* * * *$

The two-way ANOVA (image x sprint) showed a significant main effect of image for the $\mathrm{P}_{\text {Peak }}\left(\mathrm{F}_{1,11}=21.71, P<0.001, \eta_{p}{ }^{2}=0.66\right), \mathrm{W}\left(\mathrm{F}_{1,11}=56.02, P<\right.$ $\left.0.0001, \eta_{p}{ }^{2}=0.84\right)$, and $\operatorname{HR}\left(\mathrm{F}_{1,11}=6.71, P=0.025, \eta_{p}{ }^{2}=0.38\right)$. Exposure to pleasant pictures led to significantly greater peak power (Figure 1a), work (Figure 1b) and heart rate (Figure 2c) following picture onset, as compared to unpleasant 
ones. However, the two-way ANOVA (image x sprint) showed no significant main effect of sprint for $\mathrm{P}_{\text {Peak }}, \mathrm{W}$ and $\mathrm{HR}$. There was a significant interaction (sprint $\mathrm{x}$ image) effect for $\mathrm{P}_{\text {Peak }}\left(\mathrm{F}_{4,44}=6.52, P<0.001, \eta_{p}{ }^{2}=0.37\right)$ and $\mathrm{W}\left(\mathrm{F}_{4,44}=5.05, P<\right.$ $\left.0.01, \eta_{p}{ }^{2}=0.31\right)$. Post hoc tests revealed that the image effect was only observed during the two first sprints $(P<0.001)$ (Figure 2 a,b).

The one-way ANOVA revealed a significant effect of image for $\operatorname{PP}_{\operatorname{dec}}\left(\mathrm{F}_{1,11}=\right.$ 10.03, $\left.P<0.01, \eta_{p}{ }^{2}=0.48\right)$ and $\mathrm{W}_{\mathrm{dec}}\left(\mathrm{F}_{1,11}=5.49, P=0.039, \eta_{p}{ }^{2}=0.33\right)$, which were greater during exposure to pleasant $(8.07 \pm 0.71 \%$ and $7.69 \pm 0.64 \%)$ images (Figure 1c,d), compared to unpleasant $(5.99 \pm 0.74 \%$ and $5.97 \pm 0.93 \%)$ ones.

$* * * *$ Figure 1 near here $* * * *$

$* * * *$ Figure 2 near here $* * * *$

\section{Discussion}

According to our hypothesis, greater peak power and work were obtained in the pleasant context, compared to the unpleasant ones. Specifically, peak power and work bias scores were positive for pleasant trials and negative for unpleasant ones (Figure 1). These results demonstrated that emotional pictures affected power output during a supra-maximal task depending on whether their affective valence was pleasant or unpleasant. Whereas pleasant pictures increased performance, unpleasant ones impaired it. In line with Baron et al.'s model, the performance improvement observed in pleasant trials accounted for their associated positive affective responses, which tended to increase the motivation to produce greater exercise intensity. In contrast, negative affects experienced during unpleasant trials tended to reduce the motivation to produce a high exercise intensity, which resulted in a decrease in 
performance. Indeed, in agreement with normative valence ratings (Lang et al., 2005), SAM results indicated that, in comparison with neutral people pictures, sport and mutilation ones induced pleasant and unpleasant emotion, respectively. Thus, emotional pictures took an active part in modifying the environmental affective content, likely explaining why power output during repeated sprints was affected.

In the present study, emotional impact on power output could be explained by appetitive and defensive motivational systems activated by the viewing of pleasant and unpleasant pictures, respectively (Lang et al., 1997). Indeed, these motivational systems were considered to mediate action in order to promote individual survivals (Lang et al., 1997; Bradley, Codispoti, Cuthbert, \& Lang, 2001). A large body of the literature demonstrated that motivational system activations gave rise to physiological changes, mediated by the somatic and autonomic nervous system (Bradley et al., 2001; Bradley, Codispoti, \& Lang, 2006). For example, while sitting or standing, the passive viewing of highly unpleasant pictures (e.g. mutilation) led to a significantly larger cardiac deceleration compared to the view of pleasant or neutral pictures (Azevedo et al., 2005; Bradley, 2009). According to these previous studies, heart rate was lower in front of unpleasant pictures, compared to pleasant ones. This physiological change is reminiscent of the "fear bradycardia" and reflects a common adaptive defensive behaviour like the behavioural phenomenon of "freezing" when a potential threat is imminent (Bradley, 2009; Fanselow, 1994). Thus, the freezing-like behaviour associated with highly unpleasant pictures could explain the lower power output observed during unpleasant trials, compared to pleasant ones, as this behaviour was not compatible with the task requirements, i.e. supra-maximal effort generating over a 6-s sprint. 
Previous studies showed a link between exercise intensity and affective responses (Kilpatrick et al., 2007; Smith \& O’Connor, 2003; Tian \& Smith, 2011). While pleasant affective responses dominate during moderate exercise intensity, they decreased during high intensity exercises for the benefit of unpleasant responses (Kilpatrick et al., 2007; Tian \& Smith, 2011). In the present study, the results of affective load scores were consistent with these previous findings. Affective load scores were positive from the second sprint regardless the image category (Table 1), indicating the dominance of unpleasant responses during the supra-maximal task.

However, although affective load in the unpleasant context was greater than in the pleasant one, this difference was not significant. This lack of significance could stem from the fact that peak power and work were significantly lower in the unpleasant context, compared to the pleasant one. If peak power and work would have been similar between the pleasant and unpleasant sessions, affective load should have been higher in the unpleasant context, because of higher exercise intensity. The fact that participants produced an exercise intensity lower in the unpleasant context than in the pleasant one may be interpreted as the effect of a regulatory process to experience the exercise as less unpleasant, enabling thus the affective load score to not increase. Accordingly, if this regulatory process were reliable, it would be then relevant during training sessions to use a pleasant context to be able to produce high exercise intensity.

Moreover, emotional effects on performance were observed for the only two first sprints since emotional peak power and work bias scores were not significantly different from each other, from the third sprint to the end of the exercise. These 
results suggested that emotional effects present at the beginning of the exercise were only transient. During RSA tests, fatigue manifests as a decrease in peak power or work, which generally occurs after the first sprint (Racinais et al., 2005; Girard, Mendez-Villanueva, \& Bishop, 2011). Even if emotional pictures affected the ability to repeat sprints, as power output was also affected during the second cycling bout, it could be assumed that the fatigue generated immediately after the first sprint has interfered with image effect.

Power and work decrement values were greater in pleasant than in unpleasant trials. This result was in agreement with previous studies (Racinais et al., 2005; Billaut et al., 2011; Racinais, Perrey, Denis, \& Bishop, 2010) according to which decrement values would depend on the highest peak power or work values. The greater these values were, the greater were the decrement values. In our study, the highest peak power and work were obtained for pleasant trial, for which decrement values were the greatest. Thus, the greater decrement values observed during pleasant did not necessarily mean a greater fatigability but could simply be the consequence of a higher peak power or work (Racinais et al., 2010).

\section{Conclusion}

The results of the present study showed that emotional pictures affected power output during a supra-maximal repetitive sprint test when emotional context was changed. Peak power and work were higher for pleasant pictures compared to unpleasant ones. As exercise intensity has been shown to impact affect during exercise, the lower exercise intensity in the unpleasant session compared to the pleasant session might be viewed as the effect of a regulatory process aimed at 
making less unpleasant the exercise. If this regulatory process were relevant, the ability of participants to produce maximal power output would thus depend on whether the emotional context is pleasant or unpleasant. These findings highlighted that emotional context should be taken into account in training and competition in which maximal power output is required.

Contributorship statement: each author contributed to the conception and design, analysis and interpretation of data, the drafting of the article or revisiting it critically for important intellectual content and approved the final version to be published.

\section{References}

Azevedo, T.M., Volchan, E., Imbiriba, L.A., Rodrigues, E.C., Oliveira, J.M., Oliveira, L.F., ... Vargas, C.D. (2005). A freezing-like posture to pictures of mutilation. Psychophysiology, 42, 255-260. PMID: 15943678

Baden, D.A., McLean, T.L., Tucker, R., Noakes, T.D., \& St Clair Gibson, A. (2005). Effect of anticipation during unknown or unexpected exercise duration on rating of perceived exertion, affect, and physiological function. British Journal of Sports Medicine, 39, 742-746. PMID: 16183771

Baron, B., Moullan, F., Deruelle, F., \& Noakes, T.D. (2011). The role of emotions on pacing strategies and performance in middle and long duration sport events. British Journal of Sports Medicine, 45, 511-517. doi: 10.1136/bjsm.2009.059964 
Billaut, F., \& Basset, F.A. (2007). Effect of different recovery patterns on repeatedsprint ability and neuromuscular responses. Journal of Sports Sciences, 25, 905-913. PMID: 17474044

Billaut, F., Bishop, D.J., Schaerz, S., \& Noakes, T.D. (2011). Influence of knowledge of sprint number on pacing during repeated-sprint exercise. Medicine \& Science in Sports \& Exercise, 43, 665-672. doi: 10.1249/MSS.0b013e3181f6ee3b

Bishop, D., Spencer, M., Duffield, R., \& Lawrence, S. (2001). The validity of a repeated sprint ability test. Journal of Science and Medicine in Sport, 4, 19-29. PMID: 11339490

Borg, G.A (1982). Psychophysical bases of perceived exertion. Medicine \& Science in Sports \& Exercise, 14, 377-381. PMID: 7154893

Bradley, M.M. (2009). Natural selective attention: orienting and emotion. Psychophysiology, 46, 1-11. doi: 10.1111/j.1469-8986.2008.00702.x

Bradley, M.M., Codispoti, M., Cuthbert, B.N., \& Lang, P.J. (2001). Emotion and motivation I: defensive and appetitive reactions in picture processing. Emotion, 1, 276-298. PMID: 12934687

Bradley, M.M., Codispoti, M., \& Lang, P.J. (2006). A multi-process account of startle modulation during affective perception. Psychophysiology, 43, 486-497. PMID: 16965611

Chen, M., \& Bargh, J.A. (1999). Consequences of automatic evaluation: immediate behavioral predispositions to approach or avoid the stimulus. Personality and Social Psychology, 25, 215-224. doi: 10.1177/0146167299025002007 
Coombes, S.A., Cauraugh, J.H., \& Janelle, C.M. (2006). Emotion and movement: activation of defensive circuitry alters the magnitude of a sustained muscle contraction. Neuroscience Letters, 396, 192-196. PMID: 16376016

Coombes, S.A., Janelle, C.M., \& Duley, A.R., (2005). Emotion and motor control: movement attributes following affective picture processing. Journal of Motor Behavior, 37, 425-436. PMID: 16280313

Doré, E., Bedu, M., França, N.M., Diallo, O., Duché, P., \& Van Praagh, E. (2000). Testing peak cycling performance: effects of braking force during growth. Medicine \& Science in Sports \& Exercise, 32, 493-498. PMID: 10694137

Fanselow, M.S. (1994). Neural organization of the defensive behavior system responsible for fear. Psychonomic Bulletin \& Review, 1, 429-438. 10.3758/BF03210947

Fitzsimmons, M., Dawson, B., \& Ward, D. (1993). Cycling and running tests of repeated sprint ability. Australian Journal of Science and Medicine in Sport, $25,82-87$.

Fox, E. (2002). Processing of emotionnal facial expressions: the role of anxiety and awareness. Cognitive, Affective, \& Behavioral Neuroscience, 2, 52-63.

Gélat, T., Coudrat, L., \& Le Pellec, A. (2011). Gait initiation is affected during emotional conflict. Neuroscience Letters, 497, 64-67. doi: 10.1016/j.neulet.2011.04.030

Girard, O., Mendez-Villanueva, A., \& Bishop, D. (2011). Repeated-sprint abilityPart I. Factors contributing to fatigue. Sports Medicine, 41, 673-694. doi: $10.2165 / 11590550-000000000-00000$ 
Hillman, C.H., Rosengren, K.S., \& Smith, D.P. (2004). Emotion and motivated behavior: postural adjustments to affective picture viewing. Biological Psychology, 66, 51-62. PMID: 15019170

Kilpatrick, M., Kraemer, R., Bartholomew, J., Acevedo, E., \& Jarreau, D. (2007). Affective responses to exercise are dependent on intensity rather than total work. Medicine \& Science in Sports and Exercise, 39, 1417-1422. PMID: 17762376

Lambert, E.V., St Clair Gibson, A., \& Noakes, T.D. (2005). Complex systems model of fatigue: integrative homoeostatic control of peripheral physiological systems during exercise in humans. British Journal of Sports Medicine, 39, 5262. PMID: 15618343

Lane, A.M., Beedie, C.J., Jones, M.V., Uphill, M., \& Devonport, T.J. (2012). The BASES expert statement on emotion regulation in sport. Journal of Sports Sciences, 30,1189-1195. PMID: 17762376

Lang, P.J. (1980). Behavioral treatment and bio-behavioral assessment: computer applications. In J.B. Sidowski, J.H. Johnson, T.A. Williams (Eds.), Technology in mental health care delivery systems (pp. 119-137). Ablex, NJ: Northwood.

Lang, P.J., Bradley, M.M., \& Cuthbert, B.N. (2005). International affective picture system (IAPS): affective ratings of pictures and instruction manual. In Technical report A-6, University of Florida, Gainesville.

Lang, P.J., Bradley, M.M., \& Cuthbert, B.N. (1997). Motivated attention: affect, activation, and action. In: P.J. Lang, R.F. Simons, \& M.T. Balaban (Eds.), Attention and orienting: sensory and motivational processes (pp. 97-135). Hillsdale, NJ: Erlbaum. 
Lang, P.J., Bradley, M.M, \& Cuthbert, B.N. (1990). Emotion, attention and the startle reflex. Psychological Review, 97, 377-395. PMID: 2200076

Lang, P.J., Greenwald, M.K., Bradley, M.M., \& Hamm, A.O. (1993). Looking at pictures: affective, facial, visceral, and behavioral reactions. Psychophysiology, 30, 261-273. PMID: 8497555

Mendez-Villanueva, A., Hamer, P., \& Bishop, D. (2007). Physical fitness and performance. Fatigue responses during repeated sprints matched for initial mechanical output. Medicine \& Science in Sports \& Exercise, 39, 2219-2225. PMID: 18046194

Naugle, K.M., Joyner, J., Hass, C.J., \& Janelle, C.M. (2010). Emotional influences on locomotor behavior. Journal of Biomechanics, 43, 3099-3103. doi: 10.1016/j.jbiomech.2010.08.008

Noakes, T.D., St Clair Gibson, A., \& Lambert, E.V. (2005). From catastrophe to complexity: a novel model of integrative central neural regulation of effort and fatigue during exercise in humans: summary and conclusions. British Journal of Sports Medicine, 39, 120-124. PMID: 15665213

Pereira, M.G., Volchan, E., De Souza, G.G.L., Oliveira, L., Campagnoli, R.R., Pinheiro, W.M., \& Pessoa, L. (2006). Sustained and transient modulation of performance induced by emotional picture viewing. Emotion, 6, 622-634. PMID: 17144753

Racinais, S., Connes, P., Bischop, D., Blonc, S., \& Hue, O. (2005). Morning versus evening power output and repeated-sprint ability. Chronobiology International, 22, 1029-1039. PMID: 16393706 
Racinais, S., Perrey, S., Denis, R., \& Bishop, D. (2010). Maximal power, but not fatigability, is greater during repeated sprints performed in the afternoon. Chronobiology International, 27, 855-864. PMID: 20560715

Smith, J.C., \& O’Connor, P.J. (2003). Physical activity does not disturb the measurement of startle and corrugator responses during affective picture viewing. Biological Psychology, 63, 293-310. PMID: 12853173

St Clair Gibson, A., Lambert, E.V., Rauch, L.H.G., Tucker, R., Baden, D.A., Foster, C., \& Noakes, T.D. (2006). The role of information processing between the brain and peripheral physiological systems in pacing and perception of effort. Sports Medicine, 36, 705-722. PMID: 16869711

St Clair Gibson, A., \& Noakes, T.D. (2004). Evidence for complex system integration and dynamic neural regulation of skeletal muscle recruitment during exercise in humans. British Journal of Sports Medicine, 38, 797-806. PMID: 15562183

Stins, J.F., \& Beek., P.J (2011). Organization of voluntary stepping in response to emotion-inducing pictures. Gait \& Posture, 34, 164-168. doi: 10.1016/j.gaitpost.2011.04.002

Tian Q., \& Smith J.C. (2011). Attentional bias to emotional stimuli is altered during moderate- but not high- intensity exercise. Emotion, 11, 1415-1424. doi: $10.1037 / \mathrm{a} 0023568$

Vandewalle, H., Pérès, G., Heller, J., \& Monod, H. (1985). All-out anaerobic capacity tests on cycle ergometers: a comparative study on men and women. European Journal of Applied Physiology and Occupational Physiology, 54, 222-229. PMID: 4043052 
Table 1. Trends of peak power, heart rate and affective load during the five sprints and according to the neutral, pleasant and unpleasant pictures. Values are mean \pm SD.

\begin{tabular}{|c|c|c|c|c|c|c|}
\hline \multirow{5}{*}{$\begin{array}{c}\text { Peak } \\
\text { power } \\
\left(\mathrm{W} \cdot \mathrm{kg}^{-1}\right)\end{array}$} & & Sprint 1 & Sprint 2 & Sprint 3 & Sprint 4 & Sprint 5 \\
\hline & Neutral & $10.18 \pm 0.24$ & $9.84 \pm 0.26$ & $9.44 \pm 0.23$ & $9.10 \pm 0.24$ & $8.75 \pm 0.22$ \\
\hline & Pleasant & $10.34 \pm 0.24$ & $9.88 \pm 0.22$ & $9.43 \pm 0.22$ & $9.06 \pm 0.19$ & $8.79 \pm 0.18$ \\
\hline & Unpleasant & $9.66 \pm 0.26$ & $9.42 \pm 0.23$ & $9.29 \pm 0.22$ & $8.93 \pm 0.21$ & $8.62 \pm 0.20$ \\
\hline & $P$ & $* * *$ & $* *$ & NS & NS & NS \\
\hline \multirow{4}{*}{$\begin{array}{l}\text { Work } \\
\left(\mathrm{J}^{\mathrm{kg}} \mathrm{kg}^{-1}\right)\end{array}$} & Neutral & $53.07 \pm 1.17$ & $50.97 \pm 1.27$ & $49.45 \pm 1.17$ & $47.59 \pm 1.37$ & $46.25 \pm 1.11$ \\
\hline & Pleasant & $54.33 \pm 1.29$ & $51.84 \pm 1.15$ & $49.42 \pm 1.25$ & $48.19 \pm 1.09$ & $46.78 \pm 0.91$ \\
\hline & Unpleasant & $50.05 \pm 1.51$ & $48.70 \pm 1.29$ & $48.04 \pm 1.03$ & $46.67 \pm 0.97$ & $44.99 \pm 1.17$ \\
\hline & $P$ & $* * *$ & $* * *$ & NS & NS & NS \\
\hline \multirow{4}{*}{$\begin{array}{l}\text { Hear rate } \\
\text { (bpm) }\end{array}$} & Neutral & $139.5 \pm 4.0$ & $154.2 \pm 4.1$ & $161.2 \pm 4.3$ & $164.8+4.3$ & $165.8 \pm 4.4$ \\
\hline & Pleasant & $139.4 \pm 3.5$ & $155.2 \pm 3.5$ & $160.0 \pm 3.9$ & $163.1 \pm 3.8$ & $164.0 \pm 3.8$ \\
\hline & Unpleasant & $136.2 \pm 4.3$ & $149.1 \pm 3.9$ & $155.7 \pm 4.4$ & $159.4 \pm 4.4$ & $159.8 \pm 4.8$ \\
\hline & $P$ & $*$ & $*$ & $*$ & $*$ & * \\
\hline \multirow{4}{*}{$\begin{array}{l}\text { Affective } \\
\text { load }\end{array}$} & Neutral & $-1.17 \pm 1.29$ & $1.33 \pm 1.19$ & $3.67 \pm 1.30$ & $6.67 \pm 1.33$ & $9.00 \pm 1.17$ \\
\hline & Pleasant & $-0.83 \pm 1.29$ & $1.67 \pm 1.37$ & $4.50 \pm 1.35$ & $6.83 \pm 1.44$ & $9.50 \pm 1.46$ \\
\hline & Unpleasant & $1.0 \pm 1.00$ & $3.33 \pm 0.96$ & $5.67 \pm 0.95$ & $7.83 \pm 1.29$ & $10.33 \pm 1.47$ \\
\hline & $P$ & NS & NS & NS & NS & NS \\
\hline
\end{tabular}

$P$ : significance level for the difference between emotional bias scores; $* * *: P<$ $0.001, * *: P<0.01, *: P<0.05, \mathrm{NS}$ : not significant. 
Figure 1. Mean (and standard error) bias scores for (a) $\mathrm{P}_{\text {Peak }}$, (b) W, (c) $\mathrm{PP}_{\mathrm{dec}}$ and (d) $\mathrm{W}_{\mathrm{dec}}$ across trials. * Significant $(\mathrm{p}<0.05)$ difference between emotional bias scores.

Figure 2. Mean (and standard error) bias scores across the picture categories and sprints for (a) $\mathrm{P}_{\text {Peak }}$, (b) W, (c) HR and (d) AL. * Significant $(\mathrm{p}<0.05)$ difference between emotional bias scores. Negative bias score indicates a lower values for the emotional trial (pleasant or unpleasant) compared to the neutral trial. 